\title{
Signal intensity enhances diagnostic capacity in myocardial infarction
}

\author{
A. van der Laarse $\cdot$ E. E. van der Wall
}

Received: 20 February 2009/Accepted: 20 February 2009/Published online: 17 March 2009

(C) The Author(s) 2009. This article is published with open access at Springerlink.com

Over the past years cardiovascular magnetic resonance (CMR) imaging has become one of the most prominent noninvasive imaging modalities in cardiovascular medicine [1-5]. Using CMR imaging, a wide variety of diseases can be detected varying from coronary artery disease, myocardial viability, vein graft disease to congenital heart disease [6-18]. An interesting application of CMR is the detection and quantification of infarcted myocardium in humans and experimental animals by a technique called delayed-enhancement CMR [19-25]. With this technique a gadolinium CMR contrast agent is injected intravenously followed by a long interval in which the perfused area has lost the contrast, whereas the infarcted area has slowly gained some contrast and releases that contrast with a long delay. The infarcted area is "enhanced" by this delay and this in vivo determined infarct size has been found to correlate well with postmortem determined infarct size [2628]. Particularly in non-transmural infarction the area

Editorial comment at the article titled "Investigation of T2weighted signal intensity of infarcted myocardium and its correlation with delayed enhancement magnetic resonance imaging in a porcine model with reperfused acute myocardial infarction" by Choi et al. doi:10.1007/s10554-009-9425-6.

A. van der Laarse · E. E. van der Wall ( $₫)$ Department of Cardiology, Leiden University Medical Center, P.O. Box 9600, Leiden, The Netherlands

e-mail: e.e.van_der_wall@lumc.nl of late gadolinium enhancement correlated only weakly with the infarct size determined by perfusion scintigraphy [29]. The occurrence of microvascular obstruction causes dark zones in the area of late gadolinium enhancement as appearance of gadolinium is obstructed [30, 31]. Over time, the area of delayed gadolinium enhancement becomes progressively smaller due to scar formation and hypertrophy of surviving myocardium. These late gadolinium enhancement techniques use T1-weighted images and are used regularly in clinical cardiology and experimental research.

In this issue of the International Journal of Cardiovascular Imaging, Choi et al. [32] investigated to which extent useful information is present in T2weighted images of porcine hearts with reperfused myocardial infarction. For over 25 years it is known that in the acutely infarcted heart the signal intensity in T2-weighted images correlates well with myocardial edema [33, 34]. This "edema imaging" on T2weighted images was shown to be dependent of infarct age: edema-associated hyper-intense zones in T2weighted images resolved over time and the area of $\mathrm{T} 2$ abnormality delineated the area at risk rather than the infarcted area [35]. In the present study [32], the left anterior descending artery (LAD) was occluded for 90 or $180 \mathrm{~min}$ followed by reperfusion for $90 \mathrm{~min}$. In total 15 pigs were studied of which 9 pigs underwent $90 \mathrm{~min}$ of LAD occlusion followed by $90 \mathrm{~min}$ of reperfusion, whereas the other 6 pigs underwent $180 \mathrm{~min}$ of LAD occlusion followed by $90 \mathrm{~min}$ of reperfusion. The 
authors identified two groups of infarcts on the basis of the T2-weighted images: group A, infarcts with homogeneous and hyper-intensive signal intensity on T2-weighted images, and group B, infarcts with iso-, low-, or heterogeneous signal intensities on T2weighted images. In group B infarcts, T2-weighted images exhibited about twice as large microvascular obstructions than the T2-weighted images of group A infarcts. The contrast ratios of T2-weighted images were inversely correlated to the area of microvascular obstruction observed in late gadolinium enhancement images. It has been shown that areas of microvascular obstruction are usually filled by hemorrhage due to microvascular damage [36, 37]. Choi and colleagues found an almost 1:1 relationship between area of microvascular obstruction and the area of hemorrhage. Previously, van den Bos et al. [38] reported that signal voids on T2-weighted images of reperfused infarctions in porcine hearts were due to the presence of hemorrhage. In addition, Choi et al. found a significant inverse correlation between contrast ratio of $\mathrm{T} 2$ weighted images and area of hemorrhage determined postmortem. However, T2-weighted images are not optimal for determination of infarct size as they overestimate infarct size determined by (1) late gadolinium enhancement imaging in vivo, and (2) triphenyl tetrazolium chloride staining postmortem.

Detection of intramyocardial hemorrhage, either by $\mathrm{T} 2$-weighted images or by late gadolinium enhancement imaging (or myocardial contrast echocardiography), has prognostic value [30, 31, 38]. Patients without hemorrhage showed significant improvement in wall motion score in the weeks after acute infarction, whereas left ventricular contractile function of patients with intra-myocardial hemorrhage did not improve at 1 month follow-up [38]. An advantage of the clinical use of T2-weighted images is the fact that T2-weighted imaging detects acutely infarcted myocardium better than chronic infarction, the latter being assessed best with late gadolinium enhancement imaging. Finally, the use of gadolinium-based CMR contrast agents is contraindicated in patients with renal insufficiency (GFR $<15 \mathrm{ml} / \mathrm{min}$ ) as it may precipitate nephrogenic systemic fibrosis [39]. Therefore, several indications exist to use T2weighted images in the setting of the acute myocardial infarction. Whereas decreased T2-weighted contrast ratios significantly correlate with the extent of persistent microvascular obstruction and intra- myocardial hemorrhage, contrast enhanced imaging may contribute to early detection of myocardial injury due to myocardial infarction. The study by Choi et al. [32] underscores therefore the diagnostic capability of CMR imaging techniques in patients with acute myocardial infarction.

Open Access This article is distributed under the terms of the Creative Commons Attribution Noncommercial License which permits any noncommercial use, distribution, and reproduction in any medium, provided the original author(s) and source are credited.

\section{References}

1. van der Wall EE, Vliegen HW, de Roos A, Bruschke AV (1995) Magnetic resonance imaging in coronary artery disease. Circulation 92:2723-2739

2. Buller VG, van der Geest RJ, Kool MD, van der Wall EE, de Roos A, Reiber JH (1997) Assessment of regional left ventricular wall parameters from short axis magnetic resonance imaging using a three-dimensional extension to the improved centerline method. Invest Radiol 32:529-539

3. van Rugge FP, van der Wall EE, Bruschke AV (1992) New developments in pharmacologic stress imaging. Am Heart J 124:468-485

4. Holman ER, Buller VG, de Roos A et al (1997) Detection and quantification of dysfunctional myocardium by magnetic resonance imaging. A new three-dimensional method for quantitative wall-thickening analysis. Circulation 95:924-931

5. Bavelaar-Croon CD, Kayser HW, van der Wall EE et al (2000) Left ventricular function: correlation of quantitative gated SPECT and MR imaging over a wide range of values. Radiology 217:572-575

6. Braun S, van der Wall EE, Emanuelsson S, Kobrin I (1996) Effects of a new calcium antagonist, mibefradil (Ro 405967), on silent ischemia in patients with stable chronic angina pectoris: a multicenter placebo-controlled study. The mibefradil international study group. J Am Coll Cardiol 27:317-322

7. van Lennep JE, Westerveld HT, van Lennep HW, Zwinderman AH, Erkelens DW, van der Wall EE (2000) Apolipoprotein concentrations during treatment and recurrent coronary artery disease events. Arterioscler Thromb Vasc Biol 20:2408-2413

8. Tulevski II, Hirsch A, Sanson BJ et al (2001) Increased brain natriuretic peptide as a marker for right ventricular dysfunction in acute pulmonary embolism. Thromb Haemost 86:1193-1196

9. Molhoek SG, Bax JJ, Bleeker GB et al (2004) Comparison of response to cardiac resynchronization therapy in patients with sinus rhythm versus chronic atrial fibrillation. Am J Cardiol 94:1506-1509

10. Schuijf JD, Bax JJ, van der Wall EE (2007) Anatomical and functional imaging techniques: basically similar or fundamentally different? Neth Heart J 15:43-44 
11. Bax JJ, Lamb H, Dibbets P et al (2000) Comparison of gated single-photon emission computed tomography with magnetic resonance imaging for evaluation of left ventricular function in ischemic cardiomyopathy. Am J Cardiol 86:1299-1305

12. van Rugge FP, Holman ER, van der Wall EE, de Roos A, van der Laarse A, Bruschke AV (1993) Quantitation of global and regional left ventricular function by cine magnetic resonance imaging during dobutamine stress in normal human subjects. Eur Heart J 14:456-463

13. Nemes A, Geleijnse ML, van Geuns RJ et al (2008) Dobutamine stress MRI versus threedimensional contrast echocardiography: it's all black and white. Neth Heart J 16:217-218

14. Ypenburg C, Roes SD, Bleeker GB et al (2007) Effect of total scar burden on contrast-enhanced magnetic resonance imaging on response to cardiac resynchronization therapy. Am J Cardiol 99:657-660

15. Ypenburg C, van der Wall EE, Schalij MJ, Bax JJ (2008) Imaging in cardiac resynchronisation therapy. Neth Heart J 16:S36-S40

16. van der Wall EE, Heidendal GA, den Hollander W, Westera G, Roos JP (1980) I-123 labeled hexadecenoic acid in comparison with Thallium-201 for myocardial imaging in coronary heart disease. A preliminary study. Eur J Nucl Med 5:401-405

17. Langerak SE, Vliegen HW, de Roos A et al (2002) Detection of vein graft disease using high-resolution magnetic resonance angiography. Circulation 105:328-333

18. Oosterhof T, Mulder BJM, Vliegen HW, De Roos A (2006) Cardiovascular magnetic resonance in the follow-up of patients with corrected tetralogy of Fallot: a review. Am Heart J 151:265-272

19. van der Wall EE, van Dijkman PR, de Roos A et al (1990) Diagnostic significance of gadolinium-DTPA (diethylenetriamine penta-acetic acid) enhanced magnetic resonance imaging in thrombolytic treatment for acute myocardial infarction: its potential in assessing reperfusion. Br Heart $\mathbf{J}$ 63:12-17

20. van Dijkman PR, van der Wall EE, de Roos A et al (1990) Gadolinium-enhanced magnetic resonance imaging in acute myocardial infarction. Eur J Radiol 11:1-9

21. van Dijkman PR, van der Wall EE, de Roos A et al (1991) Acute, subacute, and chronic myocardial infarction: quantitative analysis of gadolinium-enhanced MR images. Radiology 180:147-151

22. de Roos A, Matheijssen NA, Doornbos J, van Dijkman PR, van Rugge PR, van der Wall EE (1991) Myocardial infarct sizing and assessment of reperfusion by magnetic resonance imaging: a review. Int J Card Imaging 7:133-138

23. van der Wall EE, Bax JJ (2008) Late contrast enhancement by CMR: more than scar? Int $\mathrm{J}$ Cardiovasc Imaging 24:609-611

24. van Rugge FP, Boreel JJ, van der Wall EE et al (1991) Cardiac first-pass and myocardial perfusion in normal subjects assessed by sub-second Gd-DTPA enhanced MR imaging. J Comput Assist Tomogr 15:959-965

25. de Roos A, Mohanlal RW, van Vaals JJ et al (1991) Gadolinium-DTPA-enhanced magnetic resonance imaging of the isolated rat heart after ischemia and reperfusion. Invest Radiol 26:1060-1064

26. Holman ER, Vliegen HW, van der Geest RJ et al (1995) Quantitative analysis of regional left ventricular function after myocardial infarction in the pig assessed with cine magnetic resonance imaging. Magn Reson Med 34:161-169

27. van Dijkman PR, Höld KM, van der Laarse A et al (1993) Sequential analysis of infarcted and normal myocardium in piglets using in vivo gadolinium-enhanced MR images. Magn Reson Imaging 11:207-218

28. Saraste A, Nekolla S, Schwaiger M (2008) Contrast-enhanced magnetic resonance imaging in the assessment of myocardial infarction and viability. J Nucl Cardiol 15:105-117

29. Wagner A, Mahrholdt H, Holly TA et al (2003) Contrastenhanced MRI and routine single photon emission computed tomography (SPECT) perfusion imaging for detection of subendocardial myocardial infarcts: an imaging study. Lancet 361:374-379

30. Nijveldt R, Beek AM, Hirsch A et al (2008) 'No-reflow' after acute myocardial infarction: direct visualisation of microvascular obstruction by gadolinium-enhanced CMR. Neth Heart J 16:179-181

31. Wu KC, Zerhouni EA, Judd RM et al (1998) Prognostic significance of microvascular obstruction by magnetic resonance imaging in patients with acute myocardial infarction. Circulation 97:765-772

32. Choi SH, Kang J-W, Kim S-T et al. (2009) Investigation of T2-weighted signal intensity of infarcted myocardium and its correlation with delayed enhancement magnetic resonance imaging in a porcine model with reperfused acute myocardial infarction. Int $\mathbf{J}$ Cardiovasc Imaging. doi:10.1007/s10554-009-9425-6

33. Higgins CB, Herfkens R, Lipton MJ et al (1983) Nuclear magnetic resonance imaging of acute myocardial infarction in dogs: alterations in magnetic resonance times. Am J Cardiol 52:184-188

34. Abdel-Aty H, Zagrosek A, Schulze-Menger J et al (2004) Delayed enhancement and T2-weighted cardiovascular magnetic resonance imaging differentiate acute from chronic myocardial infarction. Circulation 109:2411-2416

35. Aletras AH, Tilak GS, Natanzon A et al (2006) Retrospective determination of the area at risk for reperfused acute myocardial infarction with T2-weighted cardiac magnetic resonance imaging. Circulation 113:1865-1870

36. Stork A, Lund GK, Muellerleile K et al (2006) Characterization of the peri-infarction zone using T2-weighted MRI and delayed-enhancement MRI in patients with acute myocardial infarction. Eur Radiol 16:2350-2357

37. Asanuma T, Tanabe K, Ochiai K et al (1997) Relationship between progressive microvascular damage and intramyocardial hemorrhage in patients with reperfused anterior myocardial infarction. Circulation 96:448-453

38. van den Bos EJ, Baks T, Moelker AD et al (2006) Magnetic resonance imaging of haemorrhage within reperfused myocardial infarcts: possible interference with iron oxidelabelled cell tracking? Eur Heart J 27:1620-1626

39. Kuo PH, Kanal E, Abu-Alfa AK, Cowper SE (2007) Gadolinium-based MR contrast agents and nephrogenic systemic fibrosis. Radiology 242:647-649 